\title{
ANALISA KAPASITAS JALAN DAN DERAJAT KEJENUHAN BERDASARKAN SURVEY LALU LINTAS HARIAN RATA-RATA DI KABUPATEN PASER KALIMANTAN TIMUR
}

\author{
Rezky Anisari ${ }^{1 *}$ \\ ${ }^{1}$ Dosen Jurusan Teknik Sipil Politeknik Negeri Banjarmasin \\ e-mail: ${ }^{* 1}$ rezky_anisari@poliban.ac.id (corresponding author)
}

\begin{abstract}
Abstrak
Di Provinsi Kalimantan Timur, khususnya kota Tana Paser Kabupaten Paser mempunyai jumlah pertumbuhan penduduk yang cukup tinggi, dan merupakan kota yang cukup padat serta termasuk kota yang cukup berkembang sehingga banyak para pendatang yang hijrah untuk perdagangan hingga mencari pekerjaan. Berdasarkan hasil pencatatan Badan Pusat Statistik Tahun 2016, jumlah penduduk kota Tana Paser adalah 50.000 orang yang menjadikan kota Tana Paser sebagai kota dengan jumlah penduduk terbanyak di bagian Selatan Provinsi Kalimantan Timur.

Untuk mengatahui tingkat kepadatan lalu lintas diperlukan analisa dan survey lalu lintas, sehingga diperoleh hasil analisa sebagai berikut yaitu jalan yang disurvey dengan tingkat kepadatan paling tinggi atau nilai Degree of Saturation (DS) yang tertinggi adalah jalan M.T Haryono dengan DS senilai 0,494 dengan kapasitas jalan 1406,725 SMP/jam dan total arus yang melintasi sebesar 694,4 SMP/jam disusul kemudian jalan Untung Suropati dengan DS senilai 0,441 dengan kapasitas jalan 2134,458 SMP/jam dan total arus yang melintasi adalah sebesar 942,350 SMP/jam. Untuk jalan yang disurvey dengan tingkat kepadatan paling rendah atau nilai Degree of Saturation (DS) yang terendah adalah jalan Pelopor dengan DS senilai 0,020 dengan kapasitas jalan 2229,323 SMP/jam dan total arus yang melintasi hanya sebesar 45,100 SMP/jam kemudian jalan Sungai Tuak Sultan Hasanuddin dengan DS senilai 0,066 dengan kapasitas jalan 3305,275 SMP/jam dan total arus yang melintasi hanya sebesar 217,050 sehingga dikategorikan sepi.
\end{abstract}

Kata Kunci- kapasias jalan, derajat kejenuhan, tingkat kepadatan.

Abstract
In the province of East Kalimantan, especially the city of Tana Paser, Paser Regency, has a fairly high population growth, and is a fairly dense city and it is included as a fairly developed city hence many migrants who migrate to trade or to find a job. Based on the results of the Central Bureau of Statistics recording in 2016, the population of Tana Paser city was 50,000 people which make the city of Tana Paser as the city with the largest population in the Southern part of East Kalimantan Province.

To find out the traffic density level, it is necessary to analyze and survey the traffic, the results of the analysis show that the surveyed road with the highest density level or the highest Degree of Saturation (DS) is MT Haryono road with DS value of 0.494 with road capacity of 1406, 725 SMP / hour and total of traversing current of 694,4 SMP / hour followed by road of Untung Suropati with DS equals to 0,441 with road capacity of 2134,458 SMP / hour and total of traversing current equal to 942,350 SMP / hour. For the surveyed road with the lowest density level or the lowest Degree of Saturation (DS) is the Pelopor road with DS value of 0,020 with the road capacity of 2229,323 SMP / hour and the total traversing current is only 45,100 SMP / hour; then Sungai Tuak Sultan Hasanuddin road with DS value of 0,066 with road capacity of 3305,275 SMP / hour and total traversing current only equals to 217,050 hence the road is categorized as quiet road.

Keywords - road capacity, degree of saturation, density level. 


\section{PENDAHULUAN}

Dalam pembangunan transportasi , baik Pemerintah Pusat, Pemerintah propinsi maupun Pemerintah Kabupaten/Kota mempunyai tugas dan peranan sesuai cakupan kewenangannya masingmasing, yaitu berkewajiban untuk menyusun rencana dan merumuskan kebijakan, mengendalikan dan mengawasi perwujudan transportasi. Salah satu kewajiban yang dimaksud adalah menetapkan jaringan prasarana transportasi dan jaringan pelayanan. Khususnya dalam mendongkrak kinerja perekonomian Kabupaten Paser, pembangunan sektor transportasi dipacu dengan merujuk pada pembenahan transportasi yang serasi untuk mencapai keseimbangan pembangunan antar zona dengan mantap dan dinamis, sehingga mampu mengembangkan potensi ekonomi ekonomi daerah yang merupakan komponen ekonomi nasional, dengan jalan memanfaatkan sarana dan prasarana transportasi secara optimal sejalan peningkatan pelaksanaan desentralisasi dan otonomi daerah.

Pengembangan sistem dalam transportasi Kabupaten Paser menerapkan seluruh aspek moda yang ada, baik prasarana maupun sarana yang saling berinteraksi untuk memberikan pelayanan jasa transportasi yang efektif dan efisien baik antar simpul kegiatan sitem tranportasi. Kegiatan ini pada prinsipnya adalah rangkaian konsep masukan yang nantinya bersifat mengarahkan bagaimana tatanan sistem transportasi yang berupa jaringan transportasi dapat tertata untuk dapat mendukung pengambangan wilayah Kabupaten/Kota yang membawa konsekuensi pada tingkat keterhubungan antar kabupaten/kota dan antar Kecamatan. Di Provinsi Kalimantan Timur, khususnya kota Tana Paser Kabupaten Paser mempunyai jumlah pertumbuhan penduduk yang cukup tinggi, dan merupakan kota yang cukup padat serta termasuk kota yang cukup berkembang sehingga banyak para pendatang yang hijrah untuk perdagangan hingga mencari pekerjaan. Berdasarkan hasil pencatatan Badan Pusat Statistik Tahun 2016, jumlah penduduk kota Tana Paser adalah 50.000 orang yang menjadikan kota Tana Paser sebagai kota dengan jumlah penduduk terbanyak di bagian
Selatan Provinsi Kalimantan Timur. Dampak utama yang muncul akibat jumlah penduduk yang banyak salah satunya ialah kegiatan lalu lintas yang padat. Akibat dari kegiatan lalu lintas yang padat itu maka akan terjadilah konflik - konflik seperti pelanggaran lalu lintas, kemacetan, kecelakaan, dan juga antrian kendaraan bermotor yang panjang. Dari survey lapangan ditemukan masih adanya konflik yang terjadi pada lalu lintas, seperti yang terjadi pada persimpangan J1 Jenderal Sudirman, Persimpangan Jl. Noto Sunardi-Gajah Mada, persimpangan Jl. Iberahim Haliludi-Jl. A.Yani, persimpangan Senaken, masih sering terjadi pelanggaran lalu lintas dan antrian kendaraan bermotor yang banyak pada jam-jam sibuk. Hal inilah yang kemudian melandasi untuk dilakukannya tinjauan ulang untuk menghitung seluruh Kapasitas jdan Volume Lalu lintas seluruh jalan yang ada di Kota Tana Paser.

Maksud melakukan kegiatan ini adalah memberikan data data dan analisa lalu lintas orang dalam rangka lanjutan menyusun arah pengembangan jaringan pelayanan prasarana dan sarana transportasi dalam wilayah Kabupaten Paser, khususnya Pengembangan sistem Transportasi Kota Tana Paser, tujuannya adalah tersedianya dokumen yang bisa dijadikan pedoman pelaksanaan pembangunan transportasi untuk mewujudkan transportasi yang handal dan berkemampuan tinggi dalam menunjang dan sekaligus menggerakan dinamika pembangunan, meningkatkan mobilitas manusia dan barang. Tujuan khusus dari Survey LHR adalah : menghitung kapasitas jalan , mengatur pergerakan arus lalu lintas, mengurangi jumlah dan jenis kecelakaan (safety traffic) dan dapat dipergunakan untuk menghitung daya dukung tebal perkerasan dan lain lain.

Tujuan dari kegiatan penelitian ini adalah:

1. Mengetahui ruas jalan dengan tingkat kepadatan jalan yang paling tinggi berdasarkan kapasitas jalan dan volume laulintas serta Degree of Saturation (DS) aau derajat kejenuhan

2. Sebaliknya juga mengatahui tingkat kepadatan jalan paling rendah yang juga berdasarkan perhitungan kapasitas jalan dan volume lalu lintas serta Degree of Saturation (DS) atau derajat kejenuhan jalan tersebut. 


\section{METODE PENELITIAN}

Ruang lingkup kegiatan penyusunan Survey adalah memberikan batasan kegiatan survey pada jalan dalam kota Tana Paser sebagai berikut:

1. Melakukan inventarisasi peraturanperaturan yang terkait dengan Sistem tranportasi maupun peraturan lain yang relevan dan melakukan pengumpulan data primer dan survey antara lain survey harian lalu lintas Rata-rata

2. Data jumlah penduduk kota Tana Paser menurut Biro Pusat Statistik Kabupaten Paser pada tahun 2016 tercatat sebanyak 262.301 untuk kota Tana Paser sebanyak 63.311 Jiwa. Menurut Tamin (2000) merekomendasikan untuk populasi kota 63.311 yaitu antara 50.000 sampa 150.000 termasuk kategori kota kecil dengan ukuran sampel professional direkomendasikan berkisar 1:20 yaitu berjumlah 3165 buah sampel.

3. Nama 45 ruas jalan yang disurvey adalah : J1. Jend. Sudirman, Jl.Basuki Rahmat, JL.Mulawarman, J1. Suprapto, J1. K.S Tubun, JL.Ayani, Jl.P.Hidayat, Jl. Wahan Syahrani, JL. P.Menteri, Jl. R.A Kartini, Jl. Cipto Mangkusumo, Jl.Sultan Khalil, Jl. Pierre Tendean, Jl. Anden Oko, J1. Senaken, Jl. Diponegoro, Jl. Modang, Jl. Bhayangkara, Jl. P.Sentik, Jl. Anden Gedang, JL. R.E Martadinata, JL. K.H.Dahlan, Jl. Kandilo Bahari, J1. Cokro Aminoto, St. Hasanudin, J1 St.Iskandar, J1. Lambung Mangkurat, J1.Kesuma Bangsa, J1. M.T Hariyono, J1. Ulin, Jl. Singa Maulana, Jl. Urip Sumoharjo, Jl. Meranti, Jl. Pelopor, Jl Gajah Mada, Jl. Noto Sunardi, J1. Cendrawasih, Jl. Sungai Tuak dan J1. Untung Suropati.

Dalam melakukan penelitian ini ada beberapa langkah yang harus dilakukan agar penelitian berjalan dengan lancar. Langkah-langkah yang harus dilakukan antara lain:

\section{a. Survey Pendahuluan}

Penelitian survey pendahuluan yaitu hal pertama yang harus dilakukan untuk melihat kondisi nyata yang terjadi pada jalan yang akan dibahas. Dari survey awal ini kita dapat melihat inti dari permasalahan yang akan diajukan sebagai pokok pembahasan dari penelitian

\section{b. Pengambilan Data}

Yaitu pengambilan data primer dan sekunder yang berhubungan dengan penelitian untuk mengambilan Rekomendasi data Primer berkisar 1:20 yaitu berjumlah 3165 buah sampel. Pengumpulan data sekunder yaitu pengumpulan data dilapangan yang meliputi jumlah lajur, lebar jalan, hambatan samping, jalur, lay out jalan dan layout simpang. Pencatatan untuk tipe kendaraan yang melewati empat persimpangan pada tiap pendekat dikategorikan kedalam 4 (empat) jenis kendaraan, yaitu : Light Vehicle (LV)Kendaraan bermotor roda 4 (empat) termasuk mobil penumpang, mini bus, pick up, sedan, dan jeep, Heavy Vehicle (HV) Kendaraan bermotor lebih dari 4 (empat) roda termasuk bus, truck 2 (dua) sumbu, truck 3 (tiga) sumbu atau lebih, Motorcycle (MC) Semua kendaraan bermotor roda 2 (dua) dan roda 3 (tiga) termasuk sepeda motor, bajaj, dan tossa dan Unmotorized (UM) Kendaraan tak bermotor, termasuk sepeda, becak, dan gerobak.

\section{c. Survei LHR}

Dari data survey Lalu Lintas Harian Rata-rata (LHR) diperoleh perhitungan untuk Kapasitas Jalan yang dilewati oleh responden, derajat Kejenuhan dan untuk mendesign tebal Perkerasan

\section{Prinsip Umum}

Prinsip dasar untuk perhitungan simpang bersinyal yang diuraikan dibawah ini didasarkan pada prinsip-prinsip utama, yaitu sebagai berikut: Geometri, Perhitungan di lakukan secara terpisah untuk setiap pendekat. Satu lengan simpang dapat terdiri dari lebih dari satu pendekat, yaitu dipisahkan menjadi dua atau lebih dari satu subpendekat, Arus Lalu- Lintas Perhitungan dilakukan per-satuan jam untuk satu jam atau lebih periode, misalnya didasarkan pada arus lalu lintas rencana jam puncak pagi, siang, dan sore. 
Perhitungan Manual Kapasitas dan Derajat Kejenuhan:

$$
\mathrm{DS}=\mathrm{Q} / \mathrm{C}=(\mathrm{Q} \times \mathrm{c}) /(\mathrm{S} \times \mathrm{g})
$$

Perilaku Lalu Lintas (kualitas lalu lintas)

Berbagai ukuran perilaku lalu lintas dapat ditentukan berdasarkan pada arus lalu-lintas (Q), derajat kejenuhan (DS), dan waktu sinyal (c dan g) sebagaimana di sesuaikan dibawah ini dimana

$$
\begin{array}{lll}
\mathrm{DS} & = & \text { Derajat kejenuhan } \\
\mathrm{c}= & \text { Waktu Siklus } \\
\mathrm{C}= & \text { Kapasitas (smp/jam) dan } \\
\mathrm{Q}= & \text { arus lalu-lintas (smp/det) }
\end{array}
$$

TABEL I

Tabel Komposisi Lalu-Lintas Kendaraan Bermotor Dan Rasio Kendaraan Tak Bermotor.

\section{HASIL DAN PEMBAHASAN}

\begin{tabular}{|c|c|c|c|c|}
\hline \multirow{2}{*}{$\begin{array}{l}\text { LNkuran } \\
\text { Kota'Juta } \\
\text { punduduk }\end{array}$} & \multicolumn{3}{|c|}{ Kormposisi Lalu-Linlas Kenderan Bernotor (\%) } & \multirow{2}{*}{$\begin{array}{l}\text { Rasio Kend } \\
\text { tak hermntor } \\
\text { (UM) }\end{array}$} \\
\hline & $\begin{array}{l}\text { Kendaraan } \\
\text { ringen (LV) }\end{array}$ & $\begin{array}{l}\text { Kendaraan } \\
\text { bcral (HV) }\end{array}$ & $\begin{array}{c}\text { Sepeda } \\
\text { Molor (MC) }\end{array}$ & \\
\hline$\times 3$ juta & 60 & 4,5 & 35,5 & 0,01 \\
\hline $1-3$ juta & 55,5 & 3.5 & 41 & 0.05 \\
\hline $0,5-1$ juta & 40 & 3.0 & 57 & 0.14 \\
\hline $0,1-0,5$ juta & 63 & 2.5 & 34.5 & 0.05 \\
\hline$<0,1$ jula & 63 & 2,5 & 34,5 & 0,05 \\
\hline
\end{tabular}

Gambaran Umum Analisa

Dari data primer hasil survey wawancara rumah tangga mencatat perjalanan anggota rumah tangga dari jam 00.00-24.00. Respondennya adalah

anggota rumah tangga seperti ayah, ibu dan anak dan yang lainnya seperti kakek, nenek, asisten rumah tangga dll yang melakukan perjalanan sehingga diperoleh waktu puncak kota Tana Paser yaitu jam 07.00-09.00 WITA yang kemudian menjadi acuan untuk waktu saat survey lalu lintas harian rata-rata dengan mengcounting jenis kendaraan bermotor yang melintas 45 ruas jalan pada jam puncak tersbut. Untuk pengambilan data primer, berupa data volume lalu-lintas dilakukan dengan alat checklist yaitu dengan menghitung kendaraan yang melewati persimpangan dari masing-masing pendekat. Waktu Survey dilakukan selama 24 jam. Hasil rekapitulasi data survey lalu lintas harian rata-rata ditabulasi kedalam table yang memberikan informasi tentang jumlah motorcycle, light vehicle (sedan, jeep, suv, picup, box, angkit ,bajaj, bus mini dan truk mini, heavy vehicle yang terdiri dari bus besar, truk 2 sumbu, truk 3 sumbu dan trailer, serta umotorized.

Analisa Arus dan Kapasitas serta Degree of Saturation

Perhitungan arus lalu lintas (Q) dan Kapasitas jalan yang berdasarkan jenis kendaraan dalam Kend/jam yang kemudian dikonversi dalam satuan $\mathrm{SMP} / \mathrm{jam}$ dimana masing-masing jenis kendaraan berbeda-beda factor konversi nya menurut MKJI 1997 sebagai berikut: Motorcycle (sepeda motor) : factor konversi 0,25, Light vehicle: factor konversi 1 (Contoh: sedan, jeep, suv, picup, box, angkot ,bajaj, bus mini dan truk mini), 3. Heavy vehicle: factor konversi 1,2 (Contoh bus besar, truk 2 sumbu, truk 3 sumbu dan trailer) dan Unmotorized factor konversi 4 (Contoh sepeda, becak, andong, gerobak) Kemudian untuk menghitung kapasitas jalan menggunakan analisa MKJI 1997 dengan rumusan Kapasitas ( C ) total untuk seluruh lengan simpang adalah hasil perkalian antara kapasitas dasar (Co) untuk kondisi tertentu (ideal) dan faktor-faktor koreksi ( F ), dengan memperhitungkan pengaruh kondisi sesungguhnya terhadap kapasitas.

\section{$\mathrm{C}=$ Co $\times$ FW $\times$ FM $x$ FCS $\times$ FRSU $x$ FRT $x$ FMI}

$$
\begin{aligned}
& \text { dimana : } \\
& \mathrm{C}=\text { Kapasitas }(\mathrm{smp} / \mathrm{jam}) \\
& \mathrm{Co}=\text { Kapasitas dasar (smp/jam) }
\end{aligned}
$$

\section{Derajat Kejenuhan}

Derajat kejenuhan (DS) adalah rasio untuk arus lalu lintas (smp/jam) terhadap kapasitas pada bagian jalan tertentu, diperoleh dengan rumusan:

$$
\mathrm{DS}=\mathrm{Q}(\mathrm{smp} / \mathrm{jam}) / \mathrm{C}(\mathrm{smp} / \mathrm{jam})
$$


Dimana :

DS = derajat kejenuhan

Qsmp = arus total yang sesungguhnya (smp/jam)

C $=$ Kapasitas (smp/jam)

\section{Volume Lalu Lintas Harian Rata-rata}

Untuk perhitungan analisa volume lalu lintas harian rata-rata berdasarkan jenis kendaraan dalam Kend/jam yang kemudian dikonversi dalam satuan SMP/jam dimana masing-masing jenis kendaraan berbeda-beda factor konversi nya menurut MKJI 1997 sebagai berikut: Motorcycle (sepeda motor) : factor konversi 0,25, Light vehicle: factor konversi 1 (Contoh: sedan, jeep, suv, picup, box, angkot ,bajaj, bus mini dan truk mini), . Heavy vehicle : factor konversi 1,2 (Contoh bus besar, truk 2 sumbu, truk 3 sumbu dan trailer), dan Unmotorized factor konversi 4 (Contoh sepeda, becak, andong, gerobak)

Perhitungan Arus Lalu Lintas (Q), Kapasitas Jalan dan Degree of Sturation (DS), pada jam puncak 07.00-09.00 WITA

\section{Nama Jalan:WAHAB SAHRANI}

Motorcycle: $995 \mathrm{kend} / \mathrm{jam} * 0,25=248,75 \mathrm{SMP} / \mathrm{jam}$

LightVehicle:107kend/jam*1,0=107 SMP/jam

HeavyVehicle: $12 \mathrm{kend} / \mathrm{jam} * 1,2=12 \mathrm{SMP} / \mathrm{jam}$

Unmotorized:20kend/jam $* 4=20 \mathrm{SMP} / \mathrm{jam}$

Total arus (Q) lalu lintas di jalan Wahab Syahrani pada jam puncak sebesar 387,75 SMP/jam

Perhitungan Kapasitas Jalan Wahab Syahrani (C) berdasarkan analisa MKJI 1997:

$\mathrm{C}=\mathrm{Co} * \mathrm{FCW} * \mathrm{FCsp} * \mathrm{Fcsf} * \mathrm{Fccs}(\mathrm{SMP} / \mathrm{jam})$,

Kondisi jalan 2 lajur tidak berbagi: $\mathrm{Co}=2900$ $\mathrm{SMP} /$ jam total dua jalur.

$\mathrm{FCw}=$ lebar jalan $\quad=2,6 \mathrm{~m}$ per lajur

$\mathrm{Fcw}=0,54$

Fcsp =tanpa pemisah arah $=5 \mathrm{~m}$ kondisi $50 \%$ -

$50 \%$,

$\mathrm{Fcsp}=0,97$
Fcsf $=$ bahu jalan $=1,7 \mathrm{~m}$, kondisi low, Fcsf $=0,91$

Fccs = Ukuran kota Tana Grogot 53.000 jiwa, Fccs $=0,94$

Sehingga : ( C... dalam SMP/jam)

$\mathrm{C}=\mathrm{Co}^{*} \mathrm{FCW}^{*} \mathrm{FCsp} * \mathrm{Fcsf} * \mathrm{Fccs}$

$\mathrm{C}=2900 * 0,54 * 0,97 * 0,91 * 0,94=1259,1830$ smp/JAM

Jadi Kapasitas Jalan Wahab Syahrani pada jam puncak sebesar 1259,1830 SMP/jam

Perhitungan Degree of Saturation DS $=\mathrm{Q} / \mathrm{C}$ DS $=$ $=0,307$

Sehingga diperoleh kesimpulan bahwa jalan Wahab Syahrani lancer karena DS jauh berada dibawah angka teloransi maksimum yaitu : 0,85

Untuk rekapitulasi seluruh jalan yang ada berada di kota Tanah Grogot berdasarkan analisa volume lalu lintas harian rata-rata dan jumlah kendaraan tiap ruas jalan berdasrkan jenis kendaraan serta komposisi penggunaan ruang atau pembebanan ruas jalan perhitungan kapasitan dan degree of saturation atau derajat kejenuhan dapat dilihat pada tabel berikut ini: 
TABEL II

Resume Cone Penetration Test (CPT)

\begin{tabular}{|c|c|c|c|c|c|c|}
\hline NO & $\begin{array}{l}\text { NOMO } \\
\text { R } \\
\text { RUAS }\end{array}$ & NAMA RUAS JALAN & $\begin{array}{l}\text { PANJAN } \\
\text { G RUAS } \\
(\mathrm{km})\end{array}$ & $\begin{array}{l}\text { VOLUME } \\
\text { (SMP/jam) }\end{array}$ & $\begin{array}{l}\text { KAPASITAS } \\
(\mathrm{SMP} / \mathrm{jam})\end{array}$ & $\begin{array}{l}\text { DEGREE OF } \\
\text { SATURATI } \\
\text { ON }\end{array}$ \\
\hline 1 & K.01.01 & Jendral Sudirman & 0.606 & 1507.300 & 9748.969 & 0.154 \\
\hline 2 & K.01.02 & Basuki Rahmat & 0.125 & 529.200 & 6731.812 & 0.079 \\
\hline 3 & K.01.04 & Mulawarman & 0.200 & 140.350 & 1541.826 & 0.091 \\
\hline 4 & K.01.05 & R. Soeprapto & 0.314 & 694.700 & 2950.274 & 0.235 \\
\hline 5 & K.01.07 & KS. Tubun & 0.150 & 744.000 & 2300.471 & 0.323 \\
\hline 6 & K.01.08 & A Yani & 0.165 & 855.850 & 3104.840 & 0.276 \\
\hline 7 & K.01.09 & P. Hidayat & 0.100 & 525,650 & 3339.350 & 0.157 \\
\hline 8 & K.01.10 & Wahab Syahrani & 0.350 & 387.750 & 1259.183 & 0.308 \\
\hline 9 & K.01.12 & Pangeran Menteri & 0.913 & 881.650 & 2231.457 & 0.395 \\
\hline 10 & K.01.13 & RA. Kartini & 1.461 & 779.700 & 2183.526 & 0.357 \\
\hline 11 & K.01.14 & Dr. Cipto Mangunkusumo & 0.709 & 596.800 & 2300.471 & 0.259 \\
\hline 12 & K.01.15 & St. Khaliluddin & 0.963 & 588.400 & 2592.393 & 0.227 \\
\hline 13 & K.01.16 & KH.Dahlan & 0.406 & 587.650 & 2833.546 & 0.207 \\
\hline 14 & K.01.17 & P. Antasari & 0.254 & 587.650 & 2229.323 & 0.263 \\
\hline 15 & K.01.18 & Cut Nyak Dien & 0.101 & 562.100 & 3437.486 & 0.164 \\
\hline 16 & K.01.20 & Yos Soedarso & 0.963 & 1463.750 & 6581.203 & 0.222 \\
\hline 17 & K.01.22 & St. Abdurrahman (dolok) & 0.440 & 340.500 & 1480.763 & 0.230 \\
\hline 18 & K.01.23 & Piere Tendean & 0.862 & 770.650 & 2659.556 & 0.290 \\
\hline 19 & K.01.25 & D.I Panjaitan & 5.700 & 767.700 & 2485.567 & 0.309 \\
\hline 20 & K.01.26 & Anden Oko & 0.430 & 671.200 & 3411.044 & 0.197 \\
\hline 21 & K.01.30 & Senaken & 3.339 & 594.100 & 3411.044 & 0.174 \\
\hline 22 & K.01.32 & Diponegoro & 0.150 & 501.750 & 2253.039 & 0.223 \\
\hline 23 & K.01.33 & Modang & 0.791 & 511.150 & 2231.457 & 0.229 \\
\hline
\end{tabular}




\begin{tabular}{|l|l|l|l|l|l|l|}
\hline 24 & K.01.34 & Bhayangkara & 0.260 & 524.800 & 1480.768 & 0.354 \\
\hline 25 & K.01.35 & Panglima sentik & 0.253 & 561.750 & 339.350 & 0.168 \\
\hline 26 & K.01.36 & Anden Godang & 0.152 & 135.700 & 1511.299 & 0.090 \\
\hline 27 & K.01.37 & RE. Martadinata & 0.254 & 1262.600 & 6834.336 & 0.185 \\
\hline 28 & K.01.38 & Kandilo bahari & 0.659 & 791.200 & 5202.457 & 0.150 \\
\hline 29 & K.01.39 & HOS. Cokroaminoto & 1.220 & 683.450 & 3234.950 & 0.211 \\
\hline 30 & K.01.40 & Sultan Hasanuddin & 0.882 & 675.800 & 2833.546 & 0.238 \\
\hline 31 & K.01.41 & St. Iskandar Muda & 0.709 & 625.550 & 2538.450 & 0.246 \\
\hline 32 & K.01.42 & KH. Dewantara & 0.410 & 288.800 & 1348.868 & 0.214 \\
\hline 33 & - & Lambung Mangkurat & - & 439.450 & 1439.966 & 0.305 \\
\hline 34 & - & Kesuma Bangsa & - & 1339.450 & 6204.000 & 0.216 \\
\hline 35 & - & MT. Haryono & - & 694.400 & 1406.725 & 0.494 \\
\hline 36 & - & Ulin & - & 151.450 & 1542.800 & 0.098 \\
\hline 37 & - & Singa Maulana & - & 444.600 & 3107.640 & 0.143 \\
\hline 38 & & Urip Sumoharjo & - & 367.350 & 1541.836 & 0.238 \\
\hline 39 & - & Meranti & - & 179.550 & 1434.966 & 0.125 \\
\hline 40 & - & Pelopor & - & 45.100 & 22.29 .323 & 0.020 \\
\hline 41 & - & Gajah Mada & - & 773.450 & 3305.275 & 0.234 \\
\hline 42 & - & R.M.Noto Sunardi & - & 1010.400 & 6499.310 & 0.155 \\
\hline 43 & - & Cendrawasih & - & 860.100 & 2775.123 & 0.310 \\
\hline 44 & - & Hasanudin/ S.Tuak-Pepara & - & 217.050 & 3305.275 & 0.066 \\
\hline 45 & - & Untung Surpopati & 942.350 & 2134.458 & 0.441 \\
\hline
\end{tabular}

(Sumber: Hasil Perhitungan)

\section{KESIMPULAN}

Kesimpulan:

1. Untuk jalan yang disurvey dengan tingkat kepadatan paling tinggi atau nilai Degree of Saturation (DS) yang tertinggi adalah jalan M.T Haryono dengan DS senilai 0,494 dengan kapasitas jalan 1406,725 SMP/jam dan total arus yang melintasi sebesar 694,4 SMP/ jam disusul kemudian jalan Untung Suropati dengan DS senilai 0,441 dengan kapasitas jalan 2134,458 SMP/jam dan total arus yang melintasi adalah sebesar 942,350 $\mathrm{SMP} / \mathrm{jam}$.
2. Untuk jalan yang disurvey dengan tingkat kepadatan paling rendah atau nilai Degree of Saturation (DS) yang terendah adalah jalan Pelopor dengan DS senilai 0,020 dengan kapasitas jalan 2229,323 SMP/jam dan total arus yang melintasi hanya sebesar 45,100 SMP/ jam kemudian jalan Sungai Tuak Sultan Hasanuddin dengan DS senilai 0,066 dengan kapasitas jalan 3305,275 SMP/jam dan total arus yang melintasi hanya sebesar 217,050 sehingga dikategorikan sepi.

Saran:

1. Pengaturan perparkiran di jalan ( parking on street ) sangat dibutuhkan di beberapa ruas jalan 
semisal pada jalan Kartini dan MT Haryono, pada jam sibuk dan waktu tertentu dapat menjadikan kemacetan akibat hambatan samping parkir dan pedagang kaki lima.

2. Diperlukannya pemindai titik-titik simpangan yang akan diberikan pengaturan seperti adanya traffic light, rambu atau marka jalan dan rekomendasikan pemasangan Rambu jalan dalam kota terutama pada daerah wilayah pendidikan ( sekolah ), sarana ibadah dan rumah sakit, pasar dan rambu pengarah lainnya dan memberikan keterangan Level of Service (LOS) pada tiap ruas jalan serta perlu survey khusus untuk pemindai rambu lalu lintas.

\section{REFERENSI}

Departemen Pekerjaan Umum Direktorat Jenderal Bina Marga. 1997. Manual Kapasitas Jalan Indonesia (MKJI 1997). Jakarta.

Departemen Pekerjaan Umum Direktorat Jenderal Bina Marga. 1987. Tata Cara Perencanaan Geometrik Jalan Antar Kota. Jakarta.

Sukirman, Silvia. 2010. Perencanaan Tebal Struktur Perkerasan Jalan. Nova. Bandung.

Hendarsin, Shirley Liliawaty Tjahjono. 2000. Perencanaan Teknik Jalan Raya. Politeknik Negeri Bandung Jurusan Teknik Sipil. Bandung.

Saodang, Hamirhan. 2005. Konstruksi Jalan Raya. Nova. Bandung. 